\title{
A new and extensive population of Stuckenia $\times$ suecica in the River Suir, S.E. Ireland
}

\author{
Rosaleen Fitzgerald ${ }^{1}$; Christopher D. Preston ${ }^{2 *}$ \\ ${ }^{1}$ Leixlip, Co. Kildare, Ireland; ${ }^{2}$ Cambridge, UK
}

*Corresponding author: Christopher D. Preston: cdpr@ceh.ac.uk

This pdf constitutes the Version of Record published on $30^{\text {th }}$ June 2020

\begin{abstract}
We describe the distribution and habitat of a newly-discovered population of Stukenia $\times$ suecica (K. Richt.) Holub, the hybrid between S. pectinata (L.) Börner and S. filiformis (Pers.) Börner, encompassing a $60 \mathrm{~km}$ stretch of the River Suir in South Tipperary (v.c.H7), Ireland. As in Yorkshire, the hybrid here is outside the geographical range of its rarer parent, $S$. filiformis.
\end{abstract}

Keywords: Potamogeton; pondweed; hybrid.

\section{Introduction}

The pondweed species which until recently have been treated as Potamogeton subgenus Coleogeton are now often placed in a separate genus, Stuckenia. This treatment was recommended by Kaplan (2008) and followed by Stace (2019) in the latest edition of his New Flora. Although name changes are a nuisance, the new treatment makes good sense both because of clear morphological differences between the two genera and because there are numerous hybrids within the more narrowly defined genera but none is known between them. The two British and Irish species of Stuckenia, the widespread S. pectinata (L.) Börner and the more northerly and westerly $S$. filiformis (Pers.) Börner, are amongst those that hybridise. In Britain their hybrid, S. $\times$ suecica (K. Richt.) Holub, occurs not only within the range of the parents in Scotland but also as long-established populations in the Rivers Ure and Wharfe in Yorkshire, over $100 \mathrm{~km}$ south of the closest known site for S. filiformis (Preston et al., 1999; Stace et al., 2015). In Ireland S. $\times$ suecica was not discovered until 1989 and it has hitherto been recorded at a few sites within the range of $S$. filiformis in the west. In this paper we provide details of a newly discovered and remarkably extensive population of this hybrid in the River Suir. This population lies about $100 \mathrm{~km}$ south-east of the nearest known S. filiformis and its presence in the river provides a parallel to the occurrence of hybrid populations in the Yorkshire rivers in Britain.

The presence of $S . \times$ suecica in the Suir first came to light when CDP examined flowering specimens of Stuckenia collected by RF in August 2018 at two sites in S. Tipperary (v.c.H7), Golden (S0138) and Newcastle (S1213). Although these specimens superficially resembled $S$. pectinata, their closed leaf sheaths and sessile carpels ruled out this species and indicated that they were $S . \times$ suecica. The presence of the hybrid at two well-separated sites suggested that there might be an 
extensive population in the river, and on 7-8 August 2019 we visited a series of sites along the river and found that this is indeed the case. Voucher material has been deposited in CGE and DBN.

\section{Distribution and habitat in the Suir}

The River Suir is the third longest river in Ireland $(184 \mathrm{~km})$, much shorter than the Shannon $(360 \mathrm{~km})$ but not much shorter than its sister river the Barrow $(192 \mathrm{~km})$ to the east. It rises in the Devilsbit Mountain near Templemore, N. Tipperary (v.c.H10), soon enters S. Tipperary then flows southwards through Thurles, past Cashel and then through Caher before it comes against the hills running west-east along the Tipperary-Waterford boundary. Faced with this upland ridge the river loops north then east through Clonmel, Carrick-on-Suir and Waterford until the point where it joins the Barrow and reaches the sea at Waterford Harbour. The east-flowing stretch forms the boundary between S. Tipperary and Waterford, then Kilkenny and Waterford. For much of its length, from Thurles to the sea, the Suir and its tributaries constitute a Special Area of Conservation (designated under the EU Habitats Directive), the Lower River Suir SAC. It qualifies as such for a number of habitat features including its aquatic vegetation and fringing tall-herb communities. The species this SAC aims to protect include mammals (otter), fish (salmon and three species of lamprey) and invertebrates (white-clawed crayfish, freshwater pearl mussel).

In August 2019 we visited sites along the middle stretches of the river from Holycross, S. of Thurles, along the south-flowing stretch and the southerly loop up to the start of the east-flowing stretch at Knocklofty. The sites were almost all alongside bridges, as this was the most efficient way of surveying the river, and fortunately it was possible to find at least one suitable bridge in all seven hectads through which the river flows between Holycross and Knocklofty. All the sites we visited are within the SAC. Our survey was a rapid one and our aim was to cover as much of the river as possible rather than to carry out very detailed studies at individual sites. We were favoured by the water levels, which appeared to be low, and by two fairly bright days which provided conditions in which the aquatic plants growing in the clear water of the Suir were clearly visible.

At the most upstream site we visited, at Holycross (S0954), the river is shallow, stony and the main emergent species growing along the edge is Phalaris arundinacea. We found no Stuckenia $\times$ suecica in the river and the adjoining mill stream. Our next site downstream was Twoford Bridges (S0751) where, as the name suggests, the river consists of two shallow branches, each crossed by a bridge. The eastern branch was particularly shallow and dominated by algae; in the western branch we found a single stem of $S$. $\times$ suecica growing in water $30-35 \mathrm{~cm}$ deep amongst calcium-encrusted stones. The presence of this one rooted stem perhaps indicates that there are larger patches of the hybrid nearby.

At the next three sites downstream, bridges at Ardmayle (S0545), Camus Bridge (S0443) and Golden (S0138), the river is shallow and dominated by large stands of Schoenoplectus lacustris, which is present as some patches with just submersed leaves as well as others with the more familiar tall emergent stems (Figs. $1,2)$. At all three sites there were large stands of flowering $S . \times$ suecica growing in water $20-40 \mathrm{~cm}$ deep, and possibly deeper, rooted in the stony substrate of the river. It grew in rather pure beds with few associates intermixed, although at both 
Camus Bridge and Golden these were accompanied by the hybrid $P$. $x$ nitens $(P$. gramineus $\times$ perfoliatus), also growing in the absence of both parents.

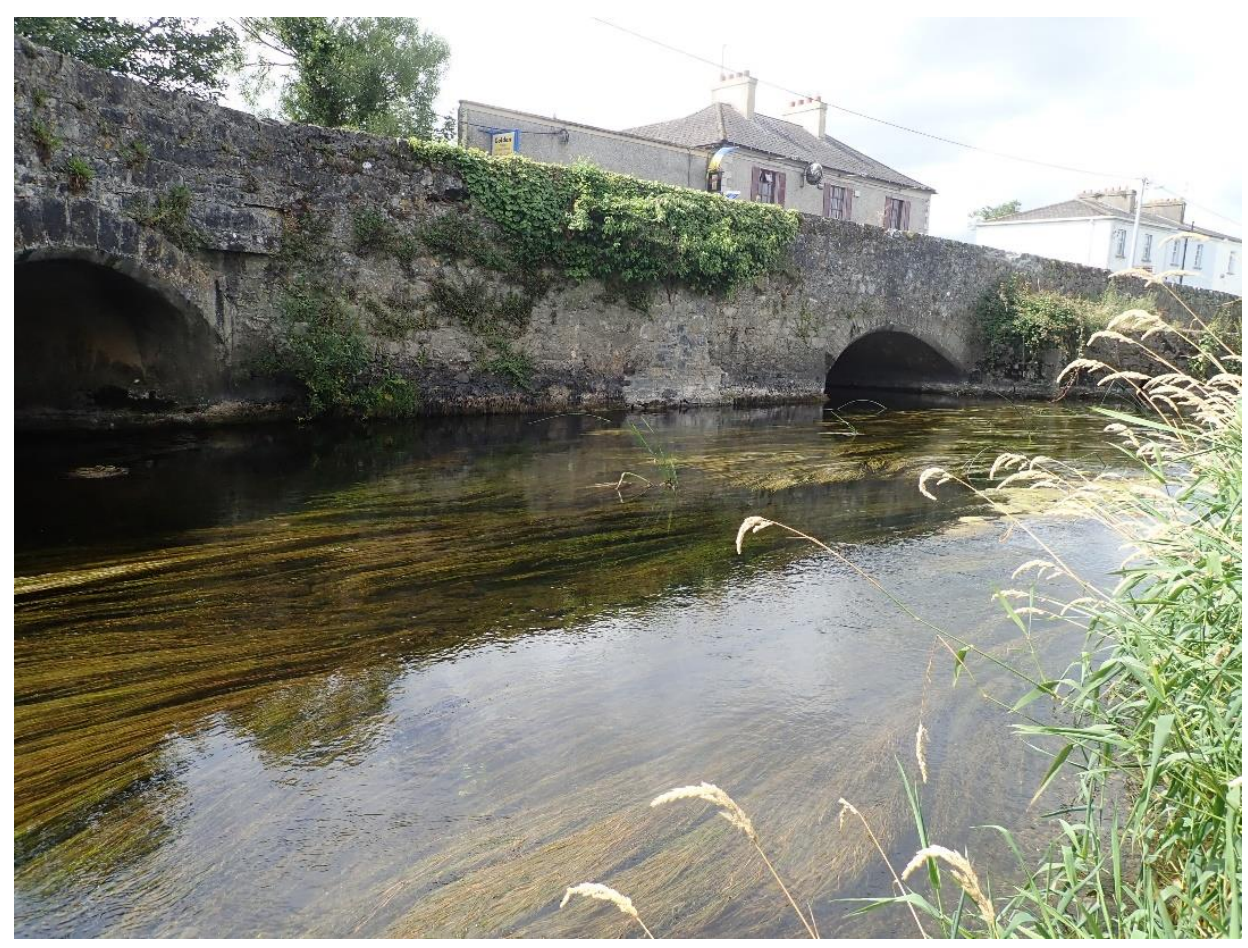

Figure 1. R. Suir at Golden, with large stands of $S . \times$ suecica in the foreground and Schoenoplectus lacustris (submerged leaves only) in the background.

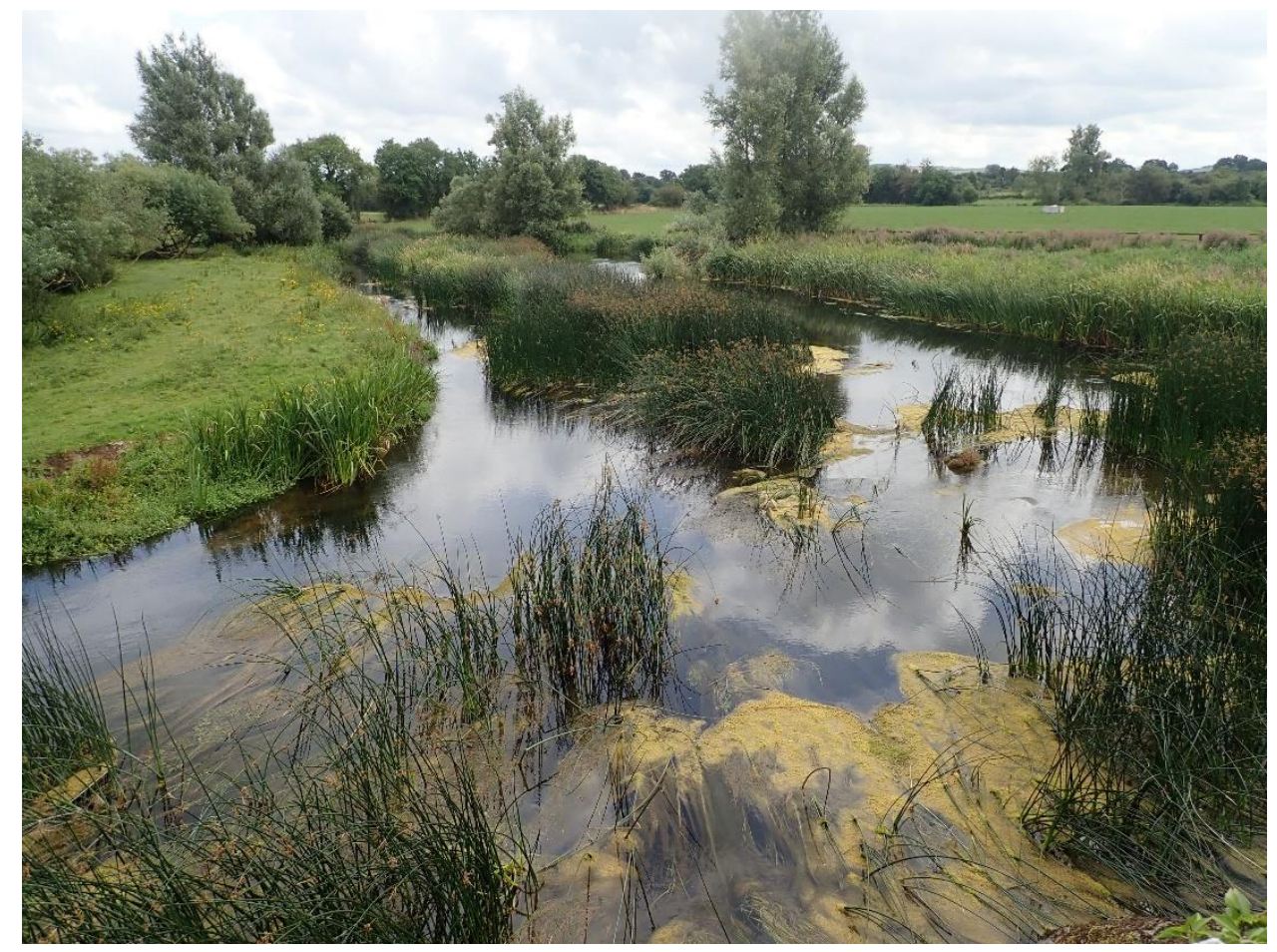

Figure 2. R. Suir at Camus Bridge, where $S . \times$ suecica grows in a stretch of river dominated by emergent stands of Schoenoplectus lacustris. 
Further downstream, as the river deepened and broadened, $S . \times$ suecica became increasingly restricted to shallower stretches of the watercourse with more stony substrates than the main channel. Below Caher, at Swiss Cottage (S0522), the beds of Schoenoplectus are found along the banks of the broader and deeper channel. We found large beds of $S . \times$ suecica on the E. side, growing in stony shallows where the flow of the water was reduced by the dense beds of Schoenoplectus immediately upstream. These grew with Lemna minor, L. trisulca, Ranunculus sp., Spirodela polyrhiza and Fontinalis antipyretica. At Ardfinnan we could find no pondweeds in the broad northerly channel of the river, but a shallower branch to the south had large beds of $S . \times$ suecica in water $40 \mathrm{~cm}$ deep over limestone stones (Fig. 3), intermixed in places with beds of Ranunculus penicillatus subsp. penicillatus. The hybrid also grew in a stream which enters this branch of the river here, in water which in places was only $10 \mathrm{~cm}$ deep, accompanied by $P$. perfoliatus, Myriophyllum spicatum, Ranunculus sp. and (on slightly raised small stony mounds in the stream) Berula erecta (Fig. 4). Further downstream, at Newcastle Bridge (S1313), S. $\times$ suecica grew in water about $40 \mathrm{~cm}$ deep at the edge of an area of shoals and river shingle dominated by Phalaris arundinacea, with a few more non-flowering plants in a stagnant pond over the river shingle here.

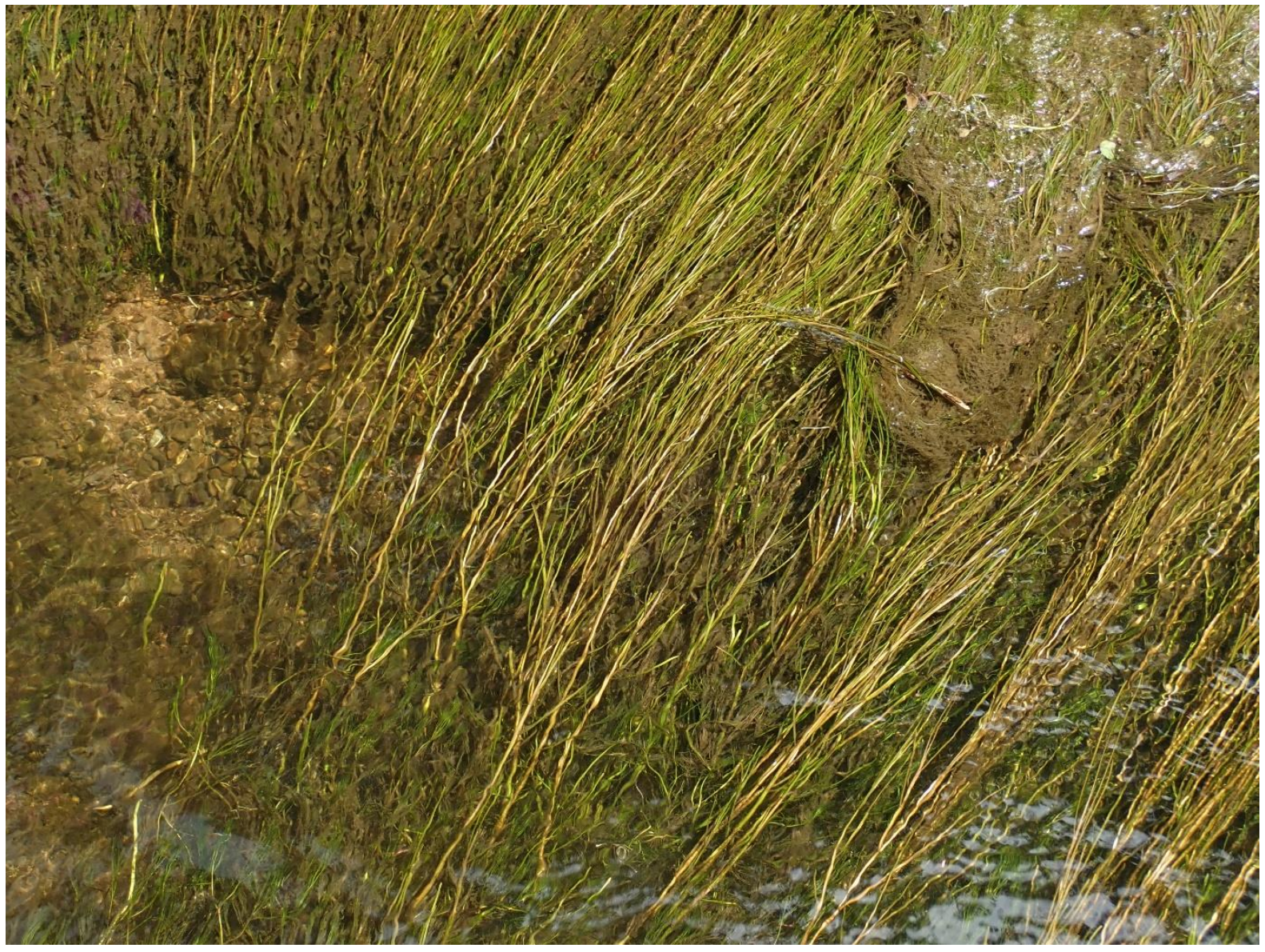

Figure 3. S. $\times$ suecica growing with Ranunculus in the S. branch of the R. Suir at Ardfinnan. 


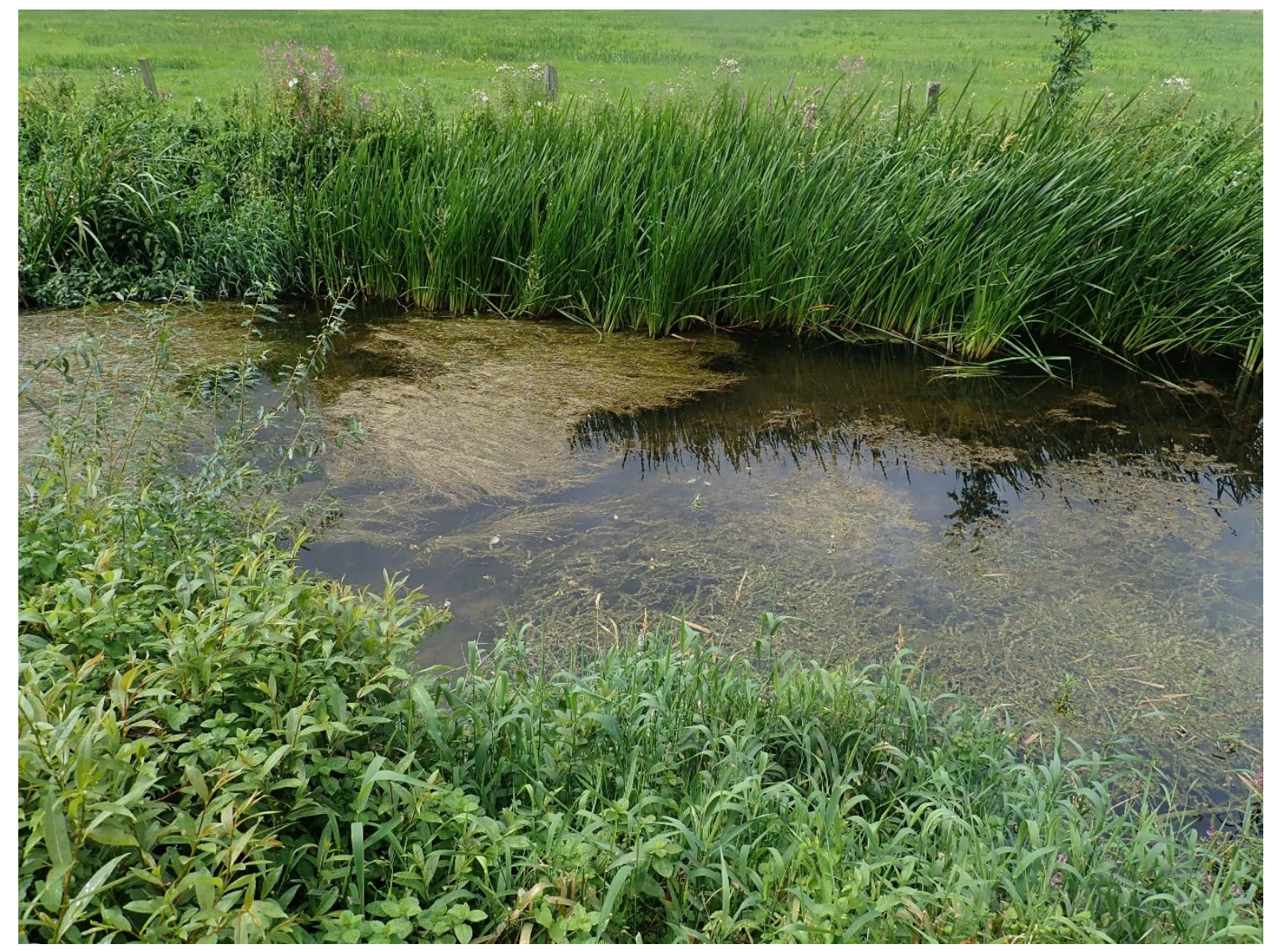

\section{Figure 4. Stream flowing into the R. Suir at Ardfinnan, which supports stands of Potamogeton perfoliatus and $S . \times$ suecica.}

The restriction of the hybrid to shallower water was most strikingly apparent at the most downstream locality we visited, at Knocklofty (S1420), where the river is the boundary between S. Tipperary and Waterford (v.c.H6). Upstream of the bridge the river is broad, smoothly flowing and tree-lined, with beds of Potamogeton $x$ angustifolius ( $P$. gramineus $x$ lucens) and $P$. $x$ nitens growing beyond the muddy margin on the Waterford side. However on the Tipperary side of the river downstream of the bridge the river breaks into shallows and there is a flowering stand of $S . \times$ suecica in water 5-20 cm deep (Fig. 5).

\section{Morphology}

We were able to collect and examine material from all the populations described above. The plants were relatively uniform (Table 1 ). The robust, branched stems were unlike those of $S$. filiformis, but the plants differed from $S$. pectinata in having sheaths which were usually closed and tubular at the base (Fig. 6), leaves with an acute rather than a finely acuminate apex and stigmas which were consistently sessile, rather than separated from the body of the carpel by a stylar neck (Fig. 7). The tubular sheaths also distinguish the hybrid from $S \times$ bottnica $(S$. pectinata $x$ vaginata), which is known from the River Liffey to the north. 

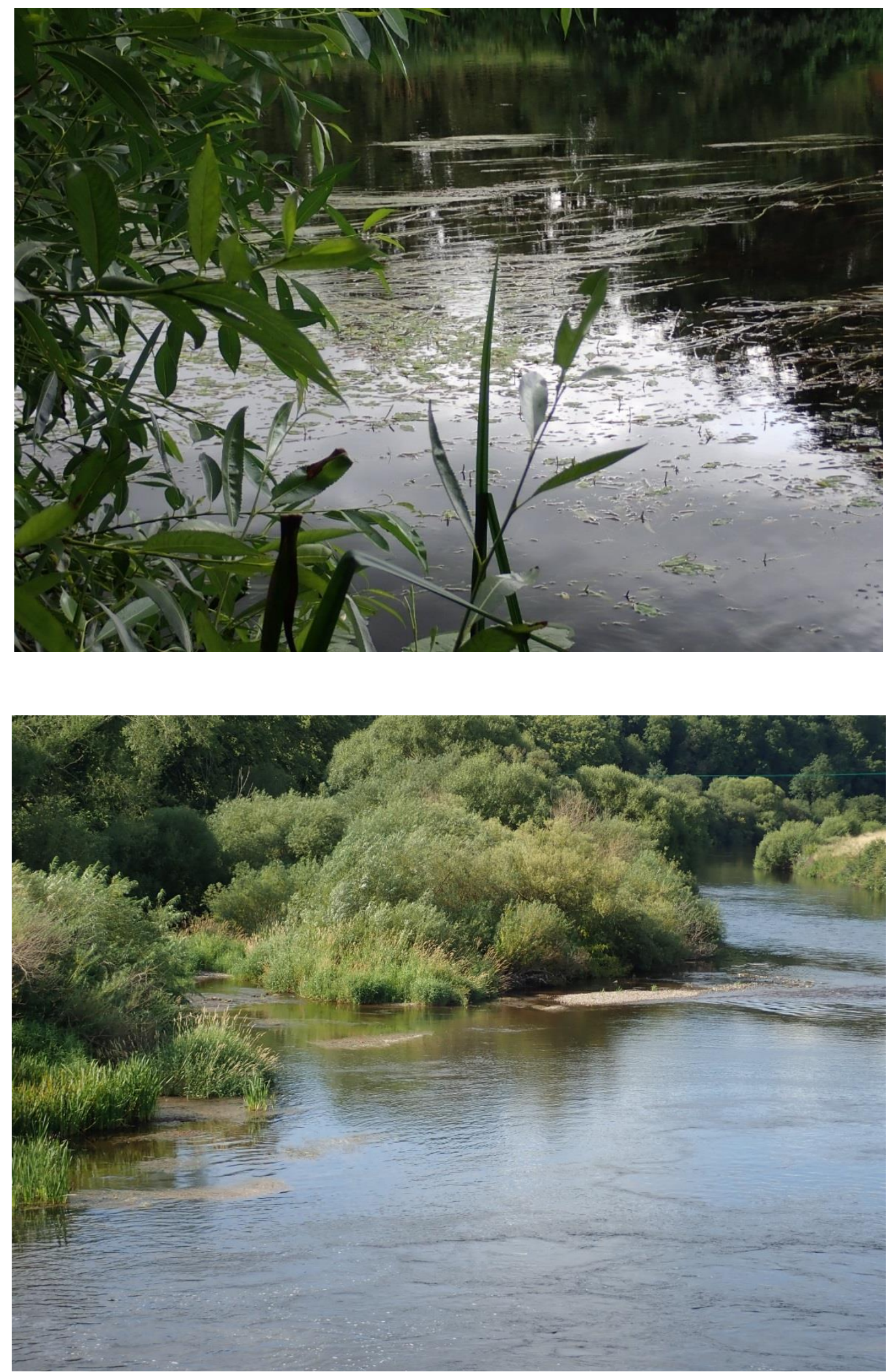

Figure 5. The R. Suir at Knocklofty. The river upstream of the bridge (top) has flowering stands of Potamogeton $\times$ angustifolius but no $S . \times$ suecica whereas downstream of the bridge (bottom) $S$. $\times$ suecica grows in the stony shallows. 

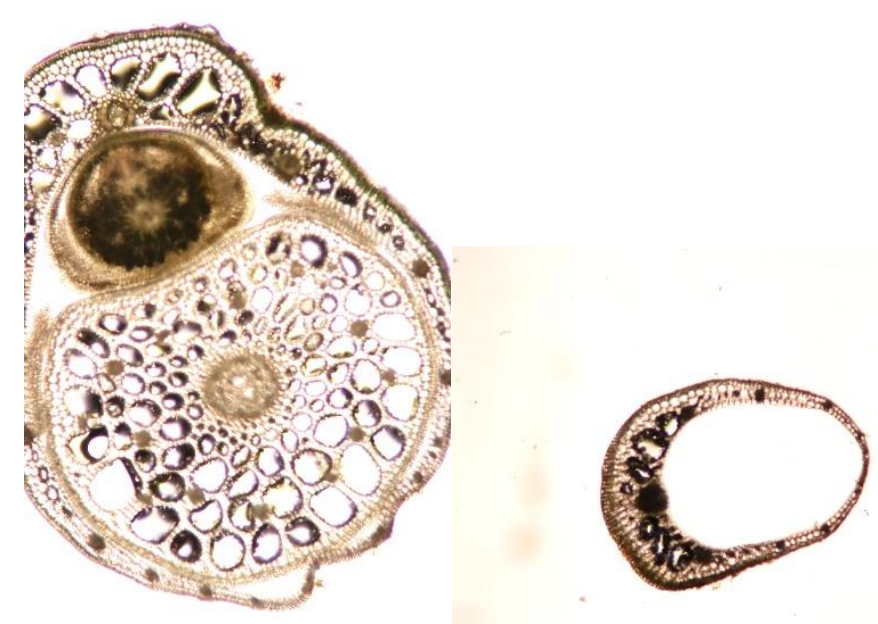

Figure 6. Cross-section of stem and surrounding tubular sheath of $S_{1} \times$ suecica from Ardmayle (left) and of an empty sheath from Golden (right).
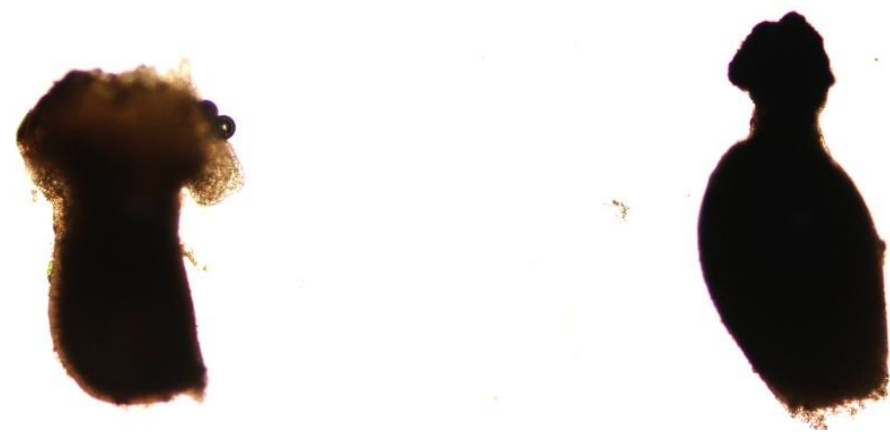

Figure 7. Carpel of $S . \times$ suecica from Ardmayle showing the sessile stigma (left) compared witha carpel of $S$. pectinata collected from a coastal pond at Ferrybank, Arklow, by C. Brady \& S. Reynolds on 8 August 2019 (right).

Table 1. Localities where $S_{.} \times$suecica was seen in the River Suir, 7-8 August 2019 , with the number of closed and open sheaths examined and the nature of the stigma. Although only young sheaths were examined, some of those recorded as open may have been closed sheaths which split before dissection.

\begin{tabular}{|l|c|c|c|c|}
\hline Locality & Grid reference & $\begin{array}{c}\text { Closed } \\
\text { sheaths }\end{array}$ & $\begin{array}{c}\text { Open } \\
\text { sheaths }\end{array}$ & Stigmas \\
\hline Twoford Bridges & S070516 & 3 & 2 & not flowering \\
\hline Ardmayle Bridge & S052459 & 13 & 4 & \pm sessile \\
\hline Camus Bridge & S046431 & 10 & 3 & sessile \\
\hline Golden & S011383 & 18 & 2 & sessile \\
\hline Swiss Cottage & S054227 & 17 & 1 & sessile \\
\hline Ardfinnan (river) & S081175 & 12 & 0 & sessile \\
\hline Ardfinnan (stream) & S080176 & 11 & 1 & sessile \\
\hline Newcastle Bridge & S130136 & 15 & 1 & sessile \\
\hline Knocklofty Bridge & S143206 & 12 & 0 & \pm sessile \\
\hline
\end{tabular}


Populations of $S . \times$ suecica differ in their mixture of parental characters (Preston et al., 1998). The Suir population is clearly one which has predominantly tubular sheaths (rather than a mixture of closed and open sheaths) and consistently sessile (rather than stalked) stigmas.

\section{Discussion}

The newly discovered population of $S . \times$ suecica in the Suir extends for at least 60 $\mathrm{km}$ of the river from Twoford Bridges downstream to Knocklofty in S. Tipperary. This clearly adds a further feature to the biological interest of the SAC, as well as another significant European population of a Stuckenia hybrid outside the range of the rarer parent. A more detailed survey of the full length of the river will be needed to establish just how frequent it is between these points. We found it by all the bridges we examined in this long stretch, but the habitat might be especially suitable for $S$. $x$ suecica in the vicinity of bridges, especially in the lower, wider and deeper stretches of the river, as bridges presumably tend to be built in places where the water is shallowest. In all its sites the hybrid apparently occurs not only in the absence of $S$. filiformis but also of its more frequent parent, $S$. pectinata. We saw no sign of this in the river, though we did confirm its presence as fruiting plants in Rockwell Lake, S0634, an ornamental lake some $5 \mathrm{~km} \mathrm{N.W}$. of the river between Golden and Swiss Cottage.

The aquatic plants of the Suir have not previously been investigated very thoroughly. J.E. Dandy's card index (BM) provides an invaluable record of the specimens of Potamogeton he examined, and includes details of three specimens of $P$. pectinatus from the River Suir in S. Tipperary, one from Camus Bridge, where it was collected by R.J. Pankhurst in 1975 (BM), and two specimens in DBN, near Clonmel (D. Moore, undated) and below Clonmel (R.M. Barrington, 1876). Camus Bridge is one of the sites where we found $S . \times$ suecica whereas Clonmel is some 6 $\mathrm{km}$ downstream of Knocklofty. It would clearly be worth checking these specimens, but unfortunately we have been unable to find any of them in an initial search in these herbaria.

The other question raised by our observations this year is how much further downstream the hybrid extends in the Suir. We hope to have an opportunity to investigate this in the future.

\section{Acknowledgements}

We thank the Dublin Naturalists' Field Club for inviting C.D.P. to visit Ireland and Maria Long for suggesting that the visit was extended to include fieldwork towards the Aquatic Plant Project - Ireland. Declan Doogue was instrumental in arranging the programme of fieldwork with County Recorders. We also thank Sylvia Reynolds for sending the material of $S$. pectinata photographed in Fig. 7.

\section{References}

Kaplan, Z. 2008. A taxonomic revision of Stuckenia (Potamogetonaceae) in Asia, with notes on the diversity and variation of the genus on a worldwide scale. Folia Geobotanica 43: 159-234.

Preston, C.D., Hollingsworth P.M. \& Gornall, R.J. 1998. Potamogeton pectinatus L. $\times$ $P$. vaginatus Turcz. ( $P . \times$ bottnicus Hagstr.), a newly identified hybrid in the British Isles. Watsonia 22: 69-82. http://archive.bsbi.org.uk/Wats22p69.pdf 
Preston, C.D., Hollingsworth P.M. \& Gornall, R.J. 1999. The distribution and habitat of Potamogeton $\times$ suecicus K. Richt. $(P$. filiformis Pers. $\times$ P. pectinatus $L$. $)$ in the British Isles. Watsonia 22: 329-342. http://archive.bsbi.org.uk/Wats22p329.pdf

Stace, C.A., Preston, C.D. \& Pearman, D.A. 2015. Hybrid Flora of the British Isles. Bristol: Botanical Society of Britain \& Ireland.

Stace, C.A. 2019. New Flora of the British Isles, $4^{\text {th }}$ ed. Middlewood Green, Suffolk: C \& M Floristics.

Copyright retained by author(s). Published by BSBI under the terms of the Creative Commons Attribution 4.0 International Public License.

ISSN: $2632-4970$

https://doi.org/10.33928/bib.2020.02.093 